\title{
Language Bases of Spelling in Writing during Early and Middle Childhood: Grounding Applications to Struggling Writers in Typical Writing Development
}

\author{
Elaine Silliman, Ruth Huntley Bahr, William Nagy and Virginia \\ Berninger
}

\section{Introduction}

A major aim of this chapter is to frame writing as a multidimensional language process for which spelling is fundamentally important. Although our main focus is on English spelling, issues related to spelling systems in other languages are also mentioned. We address the linguistic bases of spelling in morphophonemic orthographies by going beyond the transparent vs. opaque notion to an expanded perspective that emphasizes the concepts of shallow and deep orthographies and their application to spelling. For a cross-language study involving two morphophonemic orthographies on this topic, see Abbott, Fayol, Zorman, Casalis, Nagy, and Berninger (2016). Our underlying principle is that individuals access more than the alphabetic principle in learning how to spell. Indeed, they rely on multiple linguistic cues when spelling. For example, Pacton and colleagues have demonstrated the importance of orthotactics (e.g., Pacton, Borchardt, Treiman, \& Lété, 2014; Pacton, Fayol, \& Perruchet, 2005; Pacton, Perruchet, Fayol, \& Cleeremans, 2001), which refers to permissible and probable spelling patterns in written words, including letter positions and letter sequences (Berninger \& Fayol, 2008). Nunes and Bryant (2006) demonstrated the importance of morphology, which includes affixes that transform root words using suffixes and prefixes. Inflectional suffixes mark tense, number (e.g., runs, run, ran), or comparison (e.g., green, greener), while derivational suffixes often alter part of speech, and create new word meaning (e.g., person, personable). Prefixes modify meaning (e.g., justice, injustice). Hence, in learning to spell, English is a morphophonemic orthography that requires understanding not only of the alphabetic principle in learning to spell words but also the patterns of orthography and morphology and the interrelationships among phonology, orthography, and morphology and the semantic and syntactic cues that the morphology provides (Tyler \& Nagy, 1989). 
In cognitive models of writing, spelling is both a translation process for converting the thought world (semantics) into written language and a transcription process for recording the written language. Research has shown that spelling is both a window into the concepts underlying words in the writer's mind (word meaning; see Richards, Berninger, \& Fayol, 2oog; Stahl \& Nagy, 2006) and a means of translating those concepts into transcribed forms (word units comprised of letters). Thus, spelling is neither a purely motor act nor purely mechanical process but rather draws on translation and transcription processes. In this chapter, we draw on interdisciplinary research evidence from speech and language sciences, psycholinguistics, and neuroscience (Bahr, Silliman, \& Berninger, 20o9; Bahr, Silliman, Berninger, \& Dow, 2012; Garcia, Abbott, \& Berninger, 2010; Nagy, Berninger, \& Abbott, 2006; Richards et al., 2006) that demonstrates that English draws on three linguistic codes or word forms: phonology (P), orthography (O), and morphology (M). These three codes or word forms and their interrelationships are referred to as РОм throughout the chapter.

This chapter covers three main aspects. First, factors that influence learning to spell in a morphophonemic orthography are explained. Second, an evidence-based model is described that integrates ром (Bahr, Silliman, Berninger, \& Barker, 2014) — with concepts and their semantic meaning and syntactic roles (Stahl \& Nagy, 2005). The result is the creation of conventional, word-specific spellings, which are acquired in small steps across time. Lastly, because learners who struggle with writing and spelling in grade 1 typically continue to struggle in grade 3 (Costa et al., 2014) and beyond (Maughan et al., 2009), we make the case in the final section that this model of typical spelling development is useful in the assessment and instruction of students with persistent spelling difficulties, including those with language learning difficulties (Nagy, Carlisle, \& Goodwin, 2014). We also address unmet research needs for further understanding the individual needs of struggling spellers.

\section{The Importance of Spelling for Writing Development}

Cross-sectional assessment studies of typically developing writers in early and middle childhood (grades 1 to 6 , ages 6 to 12) documented that transcription skills (both spelling and handwriting) are related to the quality and length of composing (translation of thinking and concepts into written language) (for a review see Berninger, 2009). A 5-year longitudinal study of spelling (grades 1 to 5 or 3 to 7 ) beginning in grade 1 or 3 showed that only spelling consistently predicted other writing skills and often, reading skills, in the next grade 
(Abbott, Berninger, \& Fayol, 2010). Thus, even in the computer era, spelling is an important transcription skill, as well as translation skill. (Trans)scribing through handwriting and spelling enables recording in writing the outcomes of translating concepts into written language (see Hayes, 1996; Hays \& Berninger, 2014; Hayes \& Olinghouse, 2015).

\section{Two Myths Interfering with Implementation of Evidence-Based Spelling Instruction}

The first persisting myth is that spelling is just a mechanical skill and handwriting just a motor skill. For recent reviews of interdisciplinary research evidence that refutes this myth, see James, Jao, and Berninger (2015) and Longcamp, Richards, Velay, and Berninger (2017). One reason that the linguistic foundations of spelling are not widely recognized is that, historically, linguistics focused on oral language. Increasingly linguists are interested in written language, including spelling (e.g., Harris \& Perfetti, 2017; Neef, 2012; Perfetti, Rieben, \& Fayol, 1997). However, translation science is needed to implement this research, as the psycholinguistics of written spelling lags behind other efforts to implement evidence-based practices in schools, for example, in reading. Research has shown that learning to spell, that is, the word level of written language, is acquired in developmental steps across time. It may take years of formal instruction to coordinate the translation of cognitive processes into written language with the spelling of word-specific vocabulary across curriculum content areas (for a review of evidence organized by developmental stepping-stones, see Berninger, 2015).

The second myth relates to the opaqueness of morphophonemic orthographies. Although some orthographies do have consistent letter-phoneme relationships for pronouncing words (i.e., they are more transparent), the transparency of English spelling becomes evident when its foundations in morphology, as well as phonology and orthography, are understood (Nunes \& Bryant, 2006; Rueckl, 2016). For example, the same spelling unit may or may not function as a true morpheme- ful is a true morpheme in hopeful but not awful (see Stahl \& Nagy, 20o6; Tyler \& Nagy, 1989). Also, height, sight, and bite are spelling alternations (Venezky, 1995, 1999) for the long $i$ sound, which become transparent to students once they become familiar with word families. To learn word-specific spellings, developing spellers therefore need the ability to analyze РОм relationships at the word family level combined with morphemes and semantics at the lexical level (Ehri, 1980a, 198ob, 2014; Olson, Forsberg, Wise, \& Rack, 1994). Moreover, interrelationships among POM codes vary with word origin in English: Anglo-Saxon, Romance (French and Latin), and Greek (Henry, 1990, 2010). In fact, English is not hopelessly opaque if its Ром regularities are 
taught for the grade-appropriate written spellings developing writers are likely to encounter and have opportunity to use in their writing at school.

\section{The Relevance of Word Origins to Word-Specific Spellings}

\section{Anglo-Saxon Origin}

Words of Anglo-Saxon origin tend to be one or two syllables long. Not only the alphabetic principle (e.g., phonemes to one-letter spelling units, $c-a-t$; phonemes to two-letter graphemes, at word beginning and end th-i-ng) but also phonological and orthographic onset-rimes (th-ing) contribute to the phonological-orthographic relationships in spelling. Inflectional suffixes that mark number, tense, and comparison and derivational suffixes that mark part of speech, and prefixes that affect meaning of root words are also relevant to spelling. For example, one phoneme $/ \mathrm{ng} /$ corresponds to a 2-letter spelling unit in singing in the root and the other in the suffix. Hence, to correctly spell a specific word linked to a specific meaning, a speller must pay attention to each linguistic cue in Ром and coordinate all three sources of linguistic cues. If, for example, an act occurs in the present and the subject who performs it is singular, sing can be transformed to sings, or if the subject is plural, it is left as sing. If the action occurred in the past, sing can be altered to sang, illustrating that not all transformations involve adding affixes-sometimes they involve transforming the spelling and pronunciation of the root word. In the case of a derivational suffix that marks part of speech, the root word sing, a verb, might be transformed to a noun singing.

\section{Romance (French or Latinate) Origin}

Words with Romance origins (French or Latin) tend to be three to five syllables long. The final morpheme with a derivational suffix may not only create a transformed word with a new part of speech but also a phonological shift in the root word. For example, adding al to the root word, nation, not only transforms it from a noun to an adjective but also changes the pronunciation of the root word. Also, the alphabetic principle for words of Romance origin may be different from words of Anglo-Saxon origin (e.g., compare $t i$, si, or $c i$ for the Romance words and $s h$ for the Anglo-Saxon words). In addition, many words of French origin have a schwa (unstressed vowel) for which the spelling depends on the specific word spelling context in which it occurs (e.g., first $e$ in avenue and the $o$ in purpose). Again, a writer must pay attention to the Ром features of specific words and link them to meaning for a word-specific spelling that is used appropriately in specific syntactic contexts (see Altemeier, Abbott, \& Berninger, 2008). 


\section{Greek Origin}

For Greek origin words, the alphabetic principle may differ from words of other origin (e.g., $p h$ for $/ f$ /as in phone or $p s$ for $/ s /$ and $c h$ for $/ k /$ as in $p s y c h o l o g y$ ). Moreover, words of Greek origin often have bi-morphemes in which both contribute equally to creating the new word (e.g., biosphere, geography) rather than an affix transforming the root word. Such bi-morphemes of Greek origin may occur more frequently in content areas of curriculum, especially math and science.

\section{Changing Models of Spelling in a Morphophonemic Orthography}

Research evidence is mounting that spelling acquisition does not rely solely on the alphabetic principle for encoding written forms from spoken words, which is but one way of mapping phonological (phoneme) and orthographic (one-letter or two-letter graphemes) patterns to a specific unit of language. Instead, in both monolingual (e.g., Anglin, 1993; Carlisle \& Fleming, 2003; Nagy \& Townsend, 2012; Nagy et al., 2006) and bilingual children (e.g., Bahr, Silliman, Danzak, \& Wilkinson, 2015; Goodwin, Huggins, Carlo, August, \& Calderon, 2013a; Wolter \& Dilworth, 2014), spelling also depends on other processes.

1) POM coding (Bahr et al., 2009) or storing and processing POM word forms. The storage and processing also involves abstracting phonological regularities (Bourassa \& Treiman, 2014), orthographic regularities (e.g., Apel, Wolter, \& Masterson, 2006; Pacton et al., 2001), and morphological regularities (e.g., Apel, Wilson-Fowler, Brimo, \& Perrin, 2012; Deacon \& Bryant, 2006; Pacton et al., 2005).

2) Cross-code mapping of interrelationships between two (P-O,O-M, $P-O)$ or all three of the POM codes (e.g., Bahr et al., 2009, 2012; Berninger \& Fayol, 2008; Sangster \& Deacon, 2011). Since more than $50 \%$ of English words are morphologically complex (Stahl \& Nagy, 20o6), the relevance of cross-code mapping for new word learning is important for at least two reasons. First, the status of a word as one morpheme (caution) or more than one (action; root $=a c t$, derivational suffix, ion) despite a common spelling unit within each word (-ion) affects the ease or difficulty of word learning (Carlisle \& Katz, 2006). Second, morphologically complex words are integral for effective academic writing in school (Silliman, Wilkinson, \& Brea-Spahn, in press). In sum, learning to spell in a morphophonemic orthography represents a developmentally complex process in which the РОм features and their interrelationships are integrated over time into specific spellings that are also linked to specific word meanings (Stahl \& Nagy, 2005). 


\section{Factors Influencing Learning to Spell in a Morphophonemic Orthography}

In this section, critical components of the spelling process are first addressed: the level where the mapping of sound to meaning occurs through general versus word-specific knowledge, and variables influencing the depth of morphological analysis, which influences new word learning. The Word-Specific Continuum of Derivational Complexity is then introduced which integrates these three critical components: $\mathrm{P}-\mathrm{O}, \mathrm{M}-\mathrm{O}, \mathrm{P}-\mathrm{M}$, and $\mathrm{P}-\mathrm{O}-\mathrm{M}$.

\section{Factor 1: Level in System Where Mapping Occurs}

A critical issue to consider is the level in the system where mapping occurs. The concepts of shallow and deep offer a more meaningful distinction than transparent versus opaque because the latter distinction implies less graphemephoneme predictability, when in fact, regularities among orthographic and morphologic patterns render seemingly opaque relationships transparent. Consider these transparent relationships when morphology as well as phonology and orthography are considered: sign-signature, distinct-distinguish. Newman's (2010) framework for contrasting shallow and deep orthographies in alphabetic and alphasyllabary languages focuses on mapping: a) granularity (the linguistic grain-size at which phonology is mapped to the orthography, e.g., phoneme, onset-rime, syllable); b) stability (regularity) of the mapping across $\mathrm{P}-\mathrm{O}$ relationships; and c) accessibility of the mapping level in the structure of the spoken language (e.g., the extent to which phonological features are sufficiently salient for transcription into word forms). Omitted from the Newman framework, however, is the role of morphology, especially in deep orthographies such as English and French, which become shallower when morphological constancy operates (Bahr et al., 2009; Bourassa \& Treiman, 2014; Nunes, \& Bryant, 2006). That is, adding a suffix to a root word does not significantly alter the root spelling or pronunciation, such as argue - argument or magicmagical, but rather makes it shallower or closer to the surface in its accessibility (Perfetti \& Harris, 2013).

\section{Factor 2: General versus Word-Specific Knowledge}

\section{General Word Knowledge}

General spelling knowledge progresses from smaller to larger units: phonemegrapheme (1 or 2 letter) connections, phonological and orthographic onsetrime correspondences within syllables, and morphological analyses of root words and affixes (Davis \& Drouin, 2010). The comparative frequency of legal letter groups (orthotactics) (Conrad, Harris, \& Williams, 2013) may affect accessibility. Even children's early (prephonological) misspellings show unspoken 
sensitivity to orthotactic patterns and the relative statistical frequency of cooccurring grapheme patterns (Treiman \& Kessler, 2013). As an illustration of this general sensitivity, data from an analysis of superior, average, and poor spellers (Silliman, Bahr, \& Berninger, 2013) revealed that a poor speller in grade 1 spelled the compound careless as ckault, which shows the child is struggling with two critical aspects involving the grain-size of the compound. First, the child appears to parse the compound inappropriately, representing it as a single syllable. Second, it is orthographically plausible to represent the $k$ sound with $c k$; however, in American English, $c k$ can only occur after a short vowel; hence, this child's misspelling represents an implicit awareness of permissible orthotactic sequences, but not their constraints on word position. Statistical learning manifests early in learning French as well. In French, like English, consonants cannot double in word-initial position. Research showed that children recalled items without doublets better than they recalled those with doublets (Pacton et al., 2014).

\section{Word-Specific Knowledge}

Multiple encounters with word forms and their meaning relations evolve through reading and writing (Davis \& Drouin, 2010; Pacton et al., 2014) and oral language experiences (Wang, Nickels, Nation, \& Castles, 2013). These experiences result in item-specific spellings represented in a lexicon (the mental dictionary) that can be accessed during spelling and word reading. The lexical quality hypothesis (Adolf \& Perfetti, 2014) provides a framework for linking the vocabulary storehouse to the multiple sources of linguistic knowledge that underlie word-specific spelling. First, a word-specific spelling consists of phonological form/code (pronunciation), orthographic form/code (spelling), and morphological form/code (root and affixes) linked to semantics (word meaning). Second, completely specified representations are of higher lexical quality than are representations with incomplete or inaccurate linguistic features. Third, individual differences affect all aspects of learning word spelling. A larger vocabulary of familiar meanings results in more word-specific spellings of higher lexical quality (Harris \& Perfetti, 2017).

\section{Factor 3: Variables Affecting the Depth of Morphological Analysis}

The research literature has identified three variables that may contribute to deeper morphological analysis for both good and poor writers (and readers): (a) familiarity, so words are more available for analysis (Carlisle \& Fleming, 2003; Goodwin, Gilbert, \& Cho, 2013b; Treiman, Seidenberg, \& Kessler, 2015); (b) word family size for derived words generated, for example, intense - intensive, intensively, intensifiers, etc. versus those that do not generate as many, such as 
seldom-seldomly (Carlisle \& Katz, 20o6); and (c) average family frequency (AFF) for derived words. Carlisle and Katz found that derived words with higher AFF and family size were often read more accurately than were derivations from smaller and less common families.

A fourth significant variable influencing the depth of morphological analysis involves the clarity of the semantic relationship between the root word and its derived form. In a word reading study, Goodwin et al. (2013b) selected low frequency derivations based on their likely content-specific occurrence in middle school textbooks. These low frequency derivations varied as to the transparency of their meaning; for example, amazement is a lower frequency derivation and is transparent (from amaze) contrasted with spatial, which is also lower frequency but has a less transparent relationship with space. The more transparent the meaning relationship between the root word and the derivation, the larger was the effect of the word root on reading accuracy. It appears, therefore, that the morphological complexity of particular derivations can influence the stability of word-specific knowledge (Bourassa \& Treiman, 2014). It may be that morphotactic regularities compensate in learning to spell words where the semantic derivational relationships are less transparent.

Given the factors that can influence general and word-specific knowledge beyond grapheme-phoneme correspondences, the question arises how learners assemble and combine РОМ and integrate these systems with syntax in their construction of word-specific spellings of varying derivational complexity. The model depicted in Figure 6.1, the Word-Specific Continuum of Derivational Complexity, offers a template for how misspellings over time may provide insight into the eventual development of derivational complexity. In addition, the model takes into account that morphological constancy functions to make a "deep" orthography, like English, more accessible (or shallower) to writers navigating the complexities of English expression.

\section{The Word-Specific Continuum of Derivational Complexity}

Suffixes can have ambiguous meanings (Stahl \& Nagy, 2005), especially for less frequent suffixes (Bourassa \& Treiman, 2014), such as -ious. Tyler and Nagy (1989) found that knowledge of the syntactic role of derivational suffixes increased through grade 8 , whereas awareness of a suffix's statistical constraints remained challenging to master beyond grade 6 . Difficulty was attributed to the necessity for integrating morphemic with syntactic knowledge; for example, -ness attaches to adjectives (still/stillness), -ize attaches to nouns (locale/local$i z e$ ), and -ity attaches to Latinate adjectives (human/humanity). 


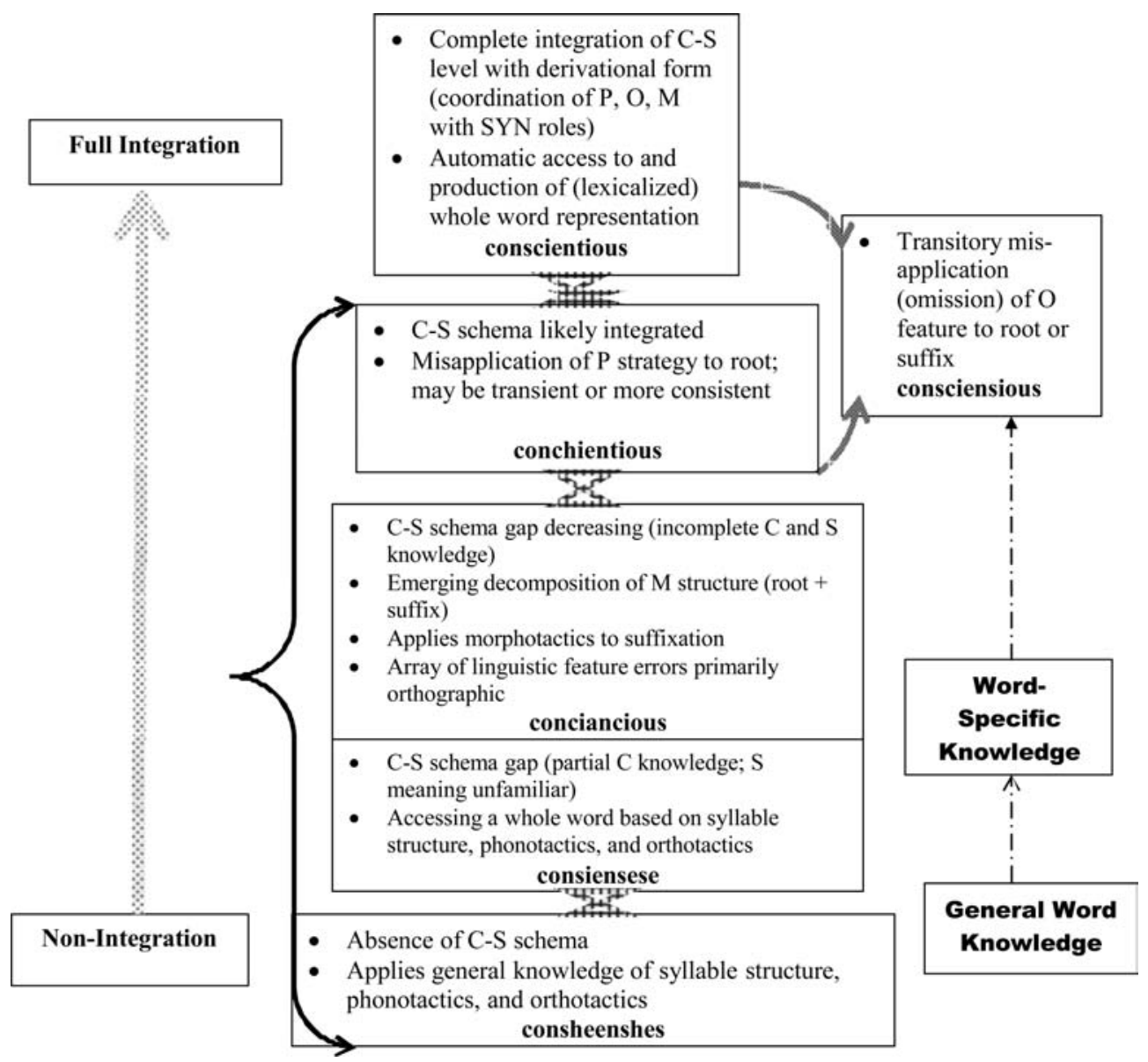

FIGURE 6.1 Emerging word-specific spelling of a complex derivation. Evolving word-specific fitting of root word and suffix relationships into the conceptual $(c)$-semantic $(s)$ schema, the morphological $(M)$, orthographic $(O)$, phonological $(P)$, and syntactic $(S Y N)$ domains for the more complex derivation 'conscientious.' Bracketed arrow indicates recursive strategies; shaded and curved gray arrows designate recursive $P$ or o strategies.

Figure 6.1 depicts conscientious, a derivation that occurs on the Wechsler Individual Achievement Spelling Test-II (Wechsler, 2001) and one with which even superior spellers in grade 7 continued to struggle (Bahr et al., 2014). Conscientious is less frequent than conscience but both words occur infrequently. The suffix is ranked as common by Fry (2004) but in the first percentile of all affixed words in printed school English by Stahl and Nagy (2006, p. 166). The difficulty that even superior spellers encountered with this derivation is certainly heightened by the disassociation between the variable pronunciations 
of this suffix and other orthographic alternations, such as -ous (religious) and -eous (courteous). The challenges these transformations present for rapid lexical access are explained by Hay's (2002) dual-level model of suffix complexity. According to this framework, which draws on derivational frequency (both root and suffix), when a root word, like conscience, occurs more frequently than the derived meaning, conscientious, then the likelihood is that the derived word will be accessed through decomposition (morphological analysis). In contrast, if a derived word (government) is employed more frequently than the root word (govern), then the meaning is likely lexicalized and the whole word then facilitates retrieval (Hay, 2002), making it shallower. Lexicalization does appear to influence how suffixes are processed in adults (Bozic, Szlachta, \& MarslenWilson, 2013).

The dotted arrow on the left side of Figure 6.1 indicates the process of integrating conceptual and semantic knowledge about derivational meaning with phonological, orthographic, and morphological knowledge, from nonintegration to full integration. The outcome is a unified representation in which form-meaning relations, including syntactic relations, are fused (Carlisle \& Goodwin, 2014; Tyler \& Nagy, 1989) and automatically accessed due to complete lexicalization. The right column with the dashed arrow shows transitions from general word knowledge to increasingly refined word-specific knowledge. The points on the continuum (the stacked boxes in the middle) show this transformational process in the learner's formulation of more accurate fittings of the conceptual-semantic schema with the complex morphophonemic and syntactic representations.

The misspelling, consheenshes (grade 1 superior speller) (Bahr et al., 2014) indicates the application of general word knowledge, including syllable structure, phonotactics, and orthotactics. The initial syllable, con-, is spelled accurately as held true for all misspellings by all participants (superior, average, and poor spellers). Moreover, all four syllables are present (con-she-en-shes), showing awareness that writing patterns can be syllabic and represented phonologically (Treiman \& Kessler, 2003). The suffix (shes for tious) reflects the application of a phonological strategy (sound-letter correspondences).

The next two misspellings, consiensese (grade 2) and conciancious (grade 3), share commonality as indices of emerging conceptual and semantic knowledge, and more refined applications of metalinguistic and word consciousness that continually evolve (Apel et al., 2012; Nagy, 2007). In the lower box, the child continues to utilize a syllabic strategy, while the upper box illustrates an attempt to access a whole word. Here, the conciancious misspelling demonstrates a decomposition of the word into its root and suffix, indicating growth in the grain size selected for analysis, along with application of morphotactics and orthotactics, $c i$ - for she and -an as an alternate spelling of the schwa vowel. 
The next point on the continuum (conchientious; grade 4) represents initial integration of the conceptual and semantic levels. The morphological ending is represented accurately, while the child continues to struggle with the linguistic features that govern the correct spelling of the root. Other orthotactically permissible misspellings of the suffix may occur as the child strives to merge conceptual and semantic knowledge with knowledge about alterations in syntactic role (e.g., consciensious; grade 6).

The last level represents complete integration of the conceptual and semantic levels with the accurate integration of phonological, orthographic, morphological, and syntactic relations. The result is automatic access to and production of the lexicalized representation (i.e., conscientious).

Thus, for typically developing writers, small steps over time result in integration of many linguistic cues into a word-specific spelling that also reflects the journey taken for learning a deep orthography with transparent relationships at a word-systems level, drawing on multiple linguistic codes (see Abbott et al., 2010, 2016). The specific nature of this journey warrants further research given the finding that the level of morphological analysis entailed in a particular task influences how a specific suffix is applied across multiple linguistic levels (Goodwin, Petscher, Carlisle, \& Mitchell, 2015).

For struggling writers, including those with language learning difficulties, this journey may be complicated, if not protracted, by the reduced quality of their lexical representations and knowledge of the relations among Ром and syntactic roles. One possibility deserving further investigation is that general word knowledge is less constricted than is word-specific knowledge. On the one hand, the finding that elementary age students with language learning problems were sensitive to the morphological constancy of simple inflections and derivations (Deacon et al., 2014) suggests general word knowledge assisted them in applying the written suffix. On the other hand, when word-specific knowledge was required (e.g., spelling of wink vs win, wins, winner), they were less accurate. The word-specific model of derivational complexity would predict this pattern, suggesting that the model may be relevant for informing educational assessment and instruction. In the final section, we address how struggling writers can be supported by approaches that emphasize the systematic and explicit integration of Ром. Of note, Ром synthesis has not been a feature of typical spelling instruction. 


\section{Applications to Struggling Writers}

Developing writers may struggle in spelling for varied reasons. Some may fall at the lower end of the normal range in their spelling ability; that is, they are at risk by virtue of being low achievers compared to age or graded peers. Others may struggle because of biologically based specific learning disabilities involving language learning. Yet others may struggle with spelling because their first language is not the same as the language of instruction used at school or they speak a dialect of that language not used in instruction at school. Or, they may be from a culture with an oral tradition and thus may not be exposed to written language in the home environment.

Regardless of why they struggle, meta-analyses have shown the benefits of explicit spelling instruction for facilitating spelling development (Graham \& Santangelo, 2014). For example, in one programmatic line of research, multiple classrooms in multiple schools and school districts were screened and children who were the lowest in spelling were randomly assigned to alternative treatments or a contact control group that received only phonological training. The results for second grade showed that the spelling instruction that taught multiple connections between phonological units and orthographic units of different grain size was most effective (Berninger et al., 1998). The results for third grade showed that the spelling instruction that taught multiple strategies for analyzing $\mathrm{P}$ and $\mathrm{O}$ units of both content and function words, which varied in syllable length, was most effective (Berninger et al., 200o). In another study that randomly assigned schools to before or after school writing clubs for low achieving writers in grade 4, results showed that adding explicit instruction in $\mathrm{M}$ with that for $\mathrm{P}$ and $\mathrm{O}$ was effective in raising writing achievement on the state assessment compared to schools that did not participate in the clubs (Berninger, Fulton, \& Abbott, 2001). However, all of these instructional studies also included activities for transferring spelling skills to composing at the syntax and text levels and taught to all levels of language close in time to create functional writing systems (Berninger. 2009).

This approach that taught $\mathrm{P}-\mathrm{O}, \mathrm{M}-\mathrm{O}, \mathrm{P}-\mathrm{M}$ and their interrelationships was also effective in teaching students in grades 4 and above with specific learning disabilities, such as dyslexia with or without co-occurring dysgraphia (impaired handwriting) (Berninger et al., 2008). Both behavioral and brain imaging data before and after instruction for children in grades 4 to 9 who met evidencebased criteria for dyslexia, characterized by spelling as well as reading disability, showed significant gains in spelling achievement and brain normalization during spelling tasks (Berninger \& Richards, 2010). This occurred after receiving instruction in $\mathrm{P}, \mathrm{O}$, and $\mathrm{M}$ awareness and their interconnections (e.g., through 
word sorts, Bear, Ivernezzi, Templeton, \& Johnston, 2015; see Berninger et al., 2008, Study 1) and/or orthographic patterns in word-specific spellings (see Berninger et al., 2008, Study 2). In both studies, instructional activities also facilitated transfer of ideas and word concepts through spelling to composing. Thus, РОм instruction can improve idea expression in written language (Bahr et al., 20o9; Carlisle \& Goodwin, 2014; Nagy et al., 2014).

However, more research is needed on effective interventions for spelling in students who have disabilities such as sensory disorders (deafness) or other kinds of specific learning disabilities, such as oral written language learning disability (Silliman \& Berninger, 2011), that may involve morphological and syntactic processing more than do dyslexia and/or dysgraphia (Arfé, Dockrell, \& Berninger, 2015). In addition, the influence of dialectal variations, second language use, and cultural traditions (see McCardle \& Berninger, 2015) also affect the acquisition of academic writing skill. The role of spelling as an instructional framework for improving the process of transcription across the range of cultural and linguistic diversity merits more in-depth investigation.

Finally, we consider how the model presented in the second section of this chapter and Figure 6.1 might inform spelling instruction for struggling writers. To begin with, teachers should give careful attention to selection of words whose spelling should be taught for learning vocabulary specific to the content areas of the curriculum (see Nagy \& Hiebert, 2011). Three suggestions for accomplishing this goal based on the POм model presented in this chapter are illustrated with teaching the spelling for conscientious (see Figure 6.1). First, engage students with new word meanings in the oral domain to teach the concept underlying the word. These practices involve the use of student-friendly definitions to strengthen conceptual-semantic connections (e.g., to get good grades, you need to put great effort in and be very careful (conscientious) about details when you study); student demonstrations of appropriate word use in varied situations, and student applications of new word meanings in unique contexts (see Beck, McKeown, \& Kucan, 2013). These activities should also focus on morphological awareness by identifying word roots through morphological analysis, demonstrating how prefixes and suffixes influence word meaning, and how derivational suffixes change syntactic roles.

Second, to build precise orthographic patterns tied to specific word positions in memory, ask students to attend visually to each letter of the word while naming each letter aloud, and then take a mental picture of all the letters in that written word, then close their eyes and "see" the written spelling in their mind's eye (Berninger et al., 2008). Next, have students look at the mental photograph in their mind's eye with their eyes closed, name letters in specific word positions selected by the teacher while the students' eyes remain closed, 
and then have them open their eyes and check those letters in their designated positions with the target written spelling. For instance, for conscientious, the teacher might ask them to name, with eyes closed, letters in the 4 th to 6th word positions and then the last five letter positions. In another learning activity, РОм interconnections can be facilitated with word sorts (Bear et al., 2015; see also Berninger et al., 2008, Study 1). Sorts can be designed to call attention to $\mathrm{P}-\mathrm{O}, \mathrm{M}-\mathrm{O}, \mathrm{M}-\mathrm{P}$, and $\mathrm{P}-\mathrm{O}-\mathrm{M}$ interrelationships, such as sorting words with similar vowel spellings into stacks representing long and short vowels (i.e., reef, beam vs. been, death). For other examples, see Berninger et al. (2008) and Goodwin et al. (2013b).

\section{Conclusions}

In summary, not only the $\mathrm{P}-\mathrm{O}, \mathrm{M}-\mathrm{O}$, and $\mathrm{P}-\mathrm{M}$ connections and their interrelationships in РОм but also semantics (vocabulary meaning) contribute to learning correct word-specific spellings. However, morphology is not synonymous with semantics. Morphology is a word that means to transform (to morph or change) a root word using affixes that result in a change in word structure (Anglo-Saxon or Romance word origin) or to transform by combining two separate words to create a new one (Greek word origin). Semantics is a bridge between the two worlds of language and thought that gives word structure to vocabulary in the language domain and meaning to vocabulary in the cognitive domain (see Stahl \& Nagy, 2006). Learning to spell so that the P, o, \& M are interrelated and linked to semantic meaning for a specific syntactic context requires knowledge of word-specific spellings. With a systems approach to assessment and instruction that takes into account РОм interconnections and their links with semantics for a specific content area of curriculum, a morphophonemic orthography becomes more transparent. However, even in the computer age, explicit instruction is needed to learn this system, and it is developed over time as the nature and complexity of words students encounter in the curriculum change. Current spell checkers detect typos but do not provide appropriate cues to correct spellings (see Rønneberg, Johansson, Mossige, Torrance, \& Uppstad, this volume). Moreover, the act of producing the letters to spell the words during the translation of thought into written words engages the mind and facilitates the thought-language translation process (James et al., 2015; Longcamp et al., 2017). As we trust this chapter has made clear, both struggling and typically developing writers benefit from systematic and ongoing spelling instruction throughout schooling. 


\section{References}

Abbott, R., Berninger, V.W., \& Fayol, M. (2010). Longitudinal relationships of levels of language in writing and between writing and reading in grades 1 to 7 . Journal of Educational Psychology, 102, 281-298. doi:10.1037/aoo19318

Abbott, R., Fayol, M., Zorman, M., Casalis, S., Nagy, W., \& Berninger, V. (2016). Relationships of French and English morphophonemic orthographies to word reading, spelling, and reading comprehension during early and middle childhood. Canadian Journal of School Psychology, 31, 305-321.doi: 10.1177/0829573516640336. https://www .ncbi.nlm.nih.gov/pmc/articles/PMC5094806

Adolf, S.M., \& Perfetti, C.A. (2014). Individual differences in word learning and reading ability. In C.A. Stone, E.R. Silliman, B.J. Ehren, \& G.P. Wallach (Eds.), Handbook of language and literacy development:Development and disorders (Second ed., pp. 246264). New York: Guilford Press.

Altemeier, L., Abbott, R., \& Berninger, V. (2008). Executive functions for reading and writing in typical literacy development and dyslexia. Journal of Clinical and Experimental Neuropsychology, 3o, 588-6o6.

Anglin, J.M. (1993). Vocabulary development: A morphological analysis. Monographs of the Society for Research in Child Development (Serial No. 238), 58 (19).

Apel, K., Wilson-Fowler, E.B., Brimo, D., \& Perrin, N.A. (2012). Metalinguistic contributions to reading and spelling in second and third grade students. Reading and Writing, 25, 1283-1305. doi: 10.1007/s11145-011-9317-8

Apel, K., Wolter, J.A., \& Masterson, J.J. (2006). Effects of phonotactic and orthotactic probabilities during fast mapping on 5 -year-olds' learning to spell. Developmental Neuropsychology, 29, 21-42.

Arfé, B., Dockrell, J., \& Berninger, V. (Eds.) (2015). Writing development in children with hearing loss, dyslexia, or oral language problems: Implications for assessment and instruction. New York: Oxford University Press.

Bahr, R.H., Silliman, E.R., Berninger, V.W., \& Baker, R.M. (2014, July). Spelling is much more than the alphabetic principle: A longitudinal analysis of derivational complexity. Paper presented at the Society for the Scientific Study of Reading, Santé Fe, NM:

Bahr, R.H., Silliman, E.R., \& Berninger, V.W. (2009). What spelling errors have to tell about vocabulary learning. In C. Wood \& V. Connelly (Eds.), Reading and spelling: Contemporary perspectives (pp. 109-129). New York: Routledge.

Bahr, R.H., Silliman, E.R., Berninger, V.W., \& Dow, M. (2012). Linguistic pattern analysis of misspellings of typically developing writers in grades 1-9. Journal of Speech, Language, and Hearing Research, 55, 1587-1599. doi:10.1044/1092-4388(2012/10-0335)

Bahr, R.H., Silliman, E.R., Danzak, R.L., \& Wilkinson, L.C. (2015). Bilingual spelling patterns in middle school: It is more than transfer. International Journal of Bilingual Education and Bilingualism, 18, 73-91. doi:10.1080/13670050.2013.878304 
Bear, D. Ivernezzi, M., Templeton, S., \& Johnston, F. (2015). Words their way: Word study for phonics, vocabulary, and spelling instruction (6th ed.). Upper Saddle River, NJ: Merrill.

Beck, I.L., McKeown, M.G., \& Kucan, L. (2013). Bringing words to life: Robust vocabulary instruction. New York: Guilford Press.

Berninger, V. (2009). Highlights of programmatic, interdisciplinary research on writing. Learning Disabilities Research \& Practice, 24, 68-79.

Berninger, V.W. (2015). Interdisciplinary frameworks for schools: Best professional practices for serving the needs of all students. Washington, DC: American Psychological Association. http://dx.doi.org/10.1037/14437-002

Berninger, V.W., \& Fayol, M. (2008). Why spelling is important and how to teach it effectively. Encyclopedia of language and literacy development (pp. 1-13). London, ON: Canadian Language and Literacy Research Network.

Berninger, V., Fulton, C., \& Abbott, R. (2001, December). Second-grade reading clubs and fourth-grade writing clubs: Empirical evaluation of extended learning for students at-risk for passing WASL. Washington Educational Research Association. Sea Tac, WA.

Berninger, V., \& Richards, T. (2010). Inter-relationships among behavioral markers, genes, brain, and treatment in dyslexia and dysgraphia. Future Neurology, 5, 597617. doi: 10.2217/fnl.10.22

Berninger, V., Vaughan, K., Abbott, R., Brooks, A., Abbott, S., Reed, E., ... Graham, S. (1998). Early intervention for spelling problems: Teaching spelling units of varying size within a multiple connections framework. Journal of Educational Psychology, $90,587-605$.

Berninger, V., Vaughan, K., Abbott, R., Brooks, A., Begay, K., Curtin, G., ... Graham, S. (2000). Language-based spelling instruction: Teaching children to make multiple connections between spoken and written words. Learning Disability Quarterly, 23, 117-135.

Berninger, V., Winn, W., Stock, P., Abbott, R., Eschen, K., Lin, C., ... Nagy, W. (20o8). Tier 3 specialized writing instruction for students with dyslexia. Reading and Writing. An Interdisciplinary Journal, 21, 95-129.

Bourassa, D.C., \& Treiman, R. (2014). Spelling development and disability in English. In C.A. Stone, E.R. Silliman, B.J. Ehren, \& G.P. Wallach(Eds.), Handbook of language and literacy: Development and disorders (Second ed., pp. 569-583). New York: Guilford Press.

Bozic, M., Szlachta, Z., \& Marslen-Wilson, W.D. (2013). Cross-linguistic parallels in processing derivational morphology: Evidence from Polish. Brain and Language, 127, $533-538$.

Carlisle, J.F., \& Goodwin, A.P. (2014). Morphemes matter: How morphological knowledge contributes to reading and writing. In C.A. Stone, E.R. Silliman, B.J. Ehren, \& 
G.P. Wallach, (Eds.), Handbook of language and literacy: Development and disorders (Second ed., pp. 265-282). New York, NY: Guilford Press.

Carlisle, J.F., \& Fleming, J. (2003). Lexical processing of morphologically complex words in the elementary years. Scientific Studies of Reading, 7, 239-253.

Carlisle, J.F., \& Stone, C.A. (2005). Exploring the role of morphemes in word reading. Reading Research Quarterly, 40, 428-449.

Carlisle, J., \& Katz, L. (2006). Effects of word and morpheme familiarity on reading of derived words. Reading and Writing, 19, 669-693. doi:10.1007/s11145-005-5766-2

Conrad, N.J., Harris, N., \& Williams, J. (2013). Individual differences in children's literacy development: The contribution of orthographic knowledge. Reading and Writing, 26, 1223-1239.

Costa, L., Unber, A., Edwards, C., Vanselous, S., Yerby, D.C., \& Hooper, S.R. (2014). The writing side. In B. Miller, P. McCardle, \& R. Long (Eds.), Teaching reading and writing: Improving instruction and student achievement (pp. 21-43). Baltimore, MD.: Paul H. Brookes.

Davis, C., \& Drouin, M. (2010). Relations between specific and general word learning. Reading Psychology, 31, 327-346.

Deacon, S.H., \& Bryant, P. (2006). Getting to the root: Young writers' sensitivity to the role of root morphemes in the spelling of inflected and derived words. Journal of Child Language, 33, 401-417.

Deacon, S.H., Cleave, P.L., Baylis, J., Fraser, J., Ingram, E., \& Perlmutter, S. (2014). The representation of roots in the spelling of children with specific language impairment. Journal of Learning Disabilities, 47, 13-21.

Ehri, L. (1980a). The development of orthographic images. In U. Frith (Ed.), Cognitive processes in spelling (pp. 311-338). London, England: Academic Press.

Ehri, L. (1980b). The role of orthographic images in learning printed words. In J.F. Kavanaugh \& R. Venezky (Eds.), Orthographic reading and dyslexia (pp. 307-332). Baltimore, MD: University Park Press.

Ehri, L.C. (2014). Orthographic mapping in the acquisition of sight word reading, spelling memory, and vocabulary learning. Scientific Studies of Reading, 18, 5-21.

Fry, E.B. (2004). The vocabulary teacher's book of lists. San Francisco: Jossey-Bass.

Garcia, N., Abbott, R.D., \& Berninger, V.W. (2010). Predicting poor, average, and superior spellers in grades 1-6 from phonological, orthographic, and morphological, spelling, or reading composites. Written Language \& Literacy, 13, 61-99.

Goodwin, A.P., Huggins, A.C., Carlo, M.S., August, D., \& Calderon, M. (2013a). Minding morphology: How morphological awareness relates to reading for English language learners. Reading and Writing, 26, 1387-1415.

Goodwin, A.P., Gilbert, J.K., \& Cho, S. (2013b). Morphological contributions to adolescent word reading: An item response approach. Reading Research Quarterly, 48, 39-6o. 
Goodwin, A.P., Petscher, Y., Carlisle, J.F., \& Mitchell, A.M. (2015). Exploring the dimensionality of morphological knowledge for adolescent readers. Journal of Research in Reading. DoI: $10.1111 / 1467-9817.12064$

Graham, S., \& Santangelo, T. (2014). Does spelling instruction make students better spellers, readers, and writers? A meta-analytic review. Reading and Writing, 27, 17031743 .

Harris, L.N., \& Perfetti, C.A. (2017). Individual differences in phonological feedback effects: Evidence for the orthographic recoding hypothesis of orthographic learning. Scientific Studies of Reading, 21, 31-45.

Hay, J. (2002). From speech perception to morphology: Affix ordering revisited. Language $78,527-555$.

Hayes, J.R. (1996). A new framework for understanding cognition and affect in writing. In C.M. Levy \& S. Ransdell (Eds.), The science of writing: Theories, methods, individual differences, and applications (pp. 1-273). Mahwah, NJ: Lawrence Erlbaum Associates.

Hayes, J.R., \& Berninger, V. (2014). Cognitive processes in writing: A framework. In Arfé, B., Dockrell, J., \& Berninger, V. (Eds.). Writing development and instruction in children with hearing, speech, and language disorders. New York: Oxford University Press.

Hayes, J.R., \& Olinghouse, N.G. (2015). Can cognitive writing models inform the design of the common core state standards? The Elementary School Journal, 115, 480-497.

Henry, M. (1990). Words: Integrated decoding and spelling instruction based on word origin and word structure. Austin, Tx: ProEd.

Henry, M. (2010). Unlocking literacy. Effective decoding and spelling instruction (2nd edition). Baltimore: Paul H. Brookes Publishing.

James, K., Jao, J.R., \& Berninger, V. (2015). The development of multi-leveled writing brain systems: Brain lessons for writing instruction. In C. MacArthur, S. Graham, \& J. Fitzgerald (Eds.), Handbook of writing research (pp. 116-129). New York: Guilford Press.

Longcamp, M., Richards, T.L., Velay, J.L., \& Berninger, V. (2017, February 7). Neuroanatomy of handwriting and related reading and writing skills in adults and children with and without learning disabilities: French-American connections. Pratiques. https://pratiques.revues.org/3155; https://www.ncbi.nlm.nih.gov/pmc/articles/ $\mathrm{PMC}_{5297261}$

Maughan, B., Messer, J., Collishaw, S., Pickles, A., Snowling, M., Yule, W., \& Rutter, M. (2009). Persistence of literacy problems: Spelling in adolescents at mid-life. Journal of Child Psychology and Psychiatry, 50, 893-901.

McCardle, P., \& Berninger, V. (Eds.) (2015). Narrowing the achievement gap for Native American students: Paying the educational debt. New York: Routledge. See http:// www.routledge.com/books/details/9780415727167. To view the video recording of 
the co-authors' conversation for the Chapter by Iisaaksiichaa Ross Braine and Glaadai Tommy Segundo on Model for Narrowing the Achievement Gap for Native Students from Middle and High School to College Graduation, please access UW omAD/College of Education Discussion: Native American Outreach at: https://www .youtube.com/watch?v=g_2jUgAwtQg

Nagy, W. (2007). Metalinguistic awareness and the vocabulary-comprehension connection. In R.K. Wagner, A.E. Muse, \& K.R. Tannenbaum (Eds.), Vocabulary acquisition: Implications for reading comprehension (pp. 52-77). New York: Guilford.

Nagy, W., Berninger, V.W., \& Abbott, R.D. (2006). Contributions of morphology beyond phonology to literacy outcomes of upper elementary and middle-school students. Journal of Educational Psychology, 98, 134-147.

Nagy, W.E., Carlisle, J.F., \& Goodwin, A.P. (2014). Morphological knowledge and literacy acquisition. Journal of Learning Disabilities, 47, 3-12.

Nagy, W.E., \& Hiebert, E.H. (2011). Toward a theory of word selection. In M.L. Kamil, P.D. Pearson, E.B. Moje, \& P. Afflerbach (Eds.), Handbook of reading research (Vol. IV, pp. 388-404). New York: Routledge.

Nagy, W., \& Townsend, D. (2012). Words as tools: Learning academic vocabulary as language acquisition. Reading Research Quarterly, 47, 91-108.

Neef, M. (2012). Translation in the context of theoretical writing system research. In M. Fayol, D. Alamargot, \& V. Berninger, (Eds.) Translation of thought to written text while composing: Advancing theory, knowledge, methods, and applications (pp. 359374). New York: Psychology Press/Taylor Francis Group.

Newman, E.H. (2010). The role of phonology in orthographically different languages. In M. Shatz \& L.C. Wilkinson (Eds.), The education of English language learners: Research to practice (pp. 108-132). New York: Guilford Press.

Nunes, T., \& Bryant, P. (2006). Improving literacy instruction through teaching morphemes. London: Routledge.

Olson, R., Forsberg, H., Wise, B., \& Rack, J. (1994). Measurement of word recognition, orthographic, and phonological skills. In G.R. Lyon (Ed.), Frames of reference for the assessment of learning disabilities (pp. 243-277). Baltimore: Brooks Publishing.

Pacton, S., Borchardt, G., Treiman, R., \& Lété, B. (2014). Learning to spell from reading: General knowledge about spelling patterns influences memory for specific words. Quarterly Journal of Experimental Psychology, 67, 1019-1036.

Pacton, S., Fayol, M., \& Perruchet, P. (2005). Children's implicit learning of graphotactic and morphological regularities. Child Development, 76, 324-339.

Pacton, S., Perruchet, P., Fayol, M., \& Cleeremans, A. (2001). Implicit learning out of the lab: The case of orthographic regularities. Journal of Experimental Psychology, 130, 401-426.

Perfetti, C.A., \& Harris, L.N. (2013). Universal reading processes are modulated by language and writing system. Language Learning and Development, 9, 296-316. 
Perfetti, C.A., Rieben, L., \& Fayol, M. (Eds.) (1977). Learning to spell: Research, theory and practice across languages. Mahwah, NJ: Lawrence Erlbaum Associated.

Richards, T.L., Aylward, E.H., Berninger, V.W., Field, K.M., Grimme, A.C., Richards, A.L., \& Nagy, W. (2006). Individual fMRI activation in orthographic mapping and morpheme mapping after orthographic or morphological spelling. Journal of Neurolinguistics, 19, 56-86.

Richards, T., Berninger, V., \& Fayol, M. (2009). fMRI activation differences between 11-year-old good and poor spellers' access in working memory to temporary and long-term orthographic representations. Journal of Neurolinguistics, 22, 327-353. doi:10.1016/j.jneuroling.2008.11.002

Rønneberg. V., Johansson, C., Mossige, M., Torrance, M., \& Uppstad, P. (this volume). Why bother with writers? Towards "Good enough" technologies for supporting dyslexics. In B. Miller, P. McCardle, \& V. Connelly (Eds.), Writing development in struggling learners: Understanding the needs of writers across the lifecourse. Leiden, The Netherlands: Brill Publishers.

Rueckl, J.G. (2016). Toward a theory of variation in the organization of the word reading system. Scientific Studies of Reading, 20, 86-97.

Sangster, L., \& Deacon, S.H. (2011). Development in children's sensitivity to the role of derivations in spelling. Canadian Journal of Experimental Psychology, 65, 133139 .

Silliman, E.R., Bahr, R.H., \& Berninger, V.W. (2013, July). Going beyond spelling accuracy: Linguistic feature patterns of superior, average, and poor spellers. Poster presented at the International Association for Research on Learning Disabilities, Boston, MA.

Silliman, E.R., \& Berninger, V.W. (2011). Cross-disciplinary dialogue about the nature of oral and written language problems in the context of developmental, academic, and phenotypic profiles. Topics in Language Disorders, 31, 6-23.

Silliman, E.R., Wilkinson, L., \& Brea-Spahn, M.R. (in press). Writing the science register and multiple levels of language: Implications for English learners. In A. Bailey, C. Mather, \& L. Wilkinson (Eds.), Language, literacy, and learning in the STEM disciplines: Language counts for English learners. New York: Routledge.

Stahl, S.A., \& Nagy, W.E. (2006). Teaching word meanings. Mahwah, NJ: Lawrence Erlbaum.

Treiman, R., \& Kessler, B. (2003). The role of letter names in the acquisition of literacy. Advances in Child Development and Behavior, 31, 105-135.

Treiman, R., \& Kessler, B. (2013). Learning to use an alphabetic writing system. Language Learning and Development, 9, 317-330.

Treiman, R., Seidenberg, M.S., \& Kessler, B. (2015). Influences on spelling: Evidence from homophones. Language, Cognition and Neuroscience, 3, 544-554.

Tyler, A., \& Nagy, W.(1989). The acquisition of English derivational morphology. Journal of Memory and Language, 28, 649-667. 
Venezky, R. (1995). From orthography to psychology to reading. In V. Berninger (Ed.), The varieties of orthographic knowledge II: Their relation to phonology, reading, and writing (pp. 23-46). Dordrecht, The Netherlands: Kluwer Academic Press.

Venezky, R.L. (1999). The American way of spelling:The structure and origins of American English orthography. New York: Guilford Press.

Wang, H., Nickels, L., Nation, K., \& Castles, A. (2013). Predictors of orthographic learning of regular and irregular words. Scientific Studies of Reading, 17, 369-384.

Wechsler, D. (2001). Wechsler Individual Achievement Test—second edition (WIAT-II). Boston, MA: Pearson.

Wolter, J.A., \& Dilworth, V. (2014). The effects of a multilinguistic morphological awareness approach for improving language and literacy. Journal of Learning Disabilities, $47,76-85$. 